\title{
Conserved miR396b-GRF Regulation Is Involved in Abiotic Stress Responses in Pitaya (Hylocereus polyrhizus)
}

\author{
A-Li Li, Zhuang Wen, Kun Yang and Xiao-Peng Wen *D \\ The Key Laboratory of Plant Resources Conservation and Germplasm Innovation in Mountainous \\ Region (Ministry of Education), Institute of Agro-Bioengineering and College of Life Sciences, \\ Guizhou University, Guiyang 550025, China; alihg0519@163.com (A.-L.L.); gzu_zwen@163.com (Z.W.); \\ kyanggz@163.com (K.Y.) \\ * Correspondence: xpwensc@hotmail.com; Tel.: +86-851-8829-0212
}

Received: 26 March 2019; Accepted: 16 May 2019; Published: 21 May 2019

\begin{abstract}
MicroRNA396 (miR396) is a conserved microRNA family that targets growth-regulating factors (GRFs), which play significant roles in plant growth and stress responses. Available evidence justifies the idea that miR396-targeted GRFs have important functions in many plant species; however, no genome-wide analysis of the pitaya (Hylocereus polyrhizus) miR396 gene has yet been reported. Further, its biological functions remain elusive. To uncover the regulatory roles of miR396 and its targets, the hairpin sequence of pitaya miR396b and the open reading frame (ORF) of its target, HpGRF6, were isolated from pitaya. Phylogenetic analysis showed that the precursor miR396b (MIR396b) gene of plants might be clustered into three major groups, and, generally, a more recent evolutionary relationship in the intra-family has been demonstrated. The sequence analysis indicated that the binding site of hpo-miR396b in HpGRF6 is located at the conserved motif which codes the conserved "RSRKPVE" amino acid in the Trp-Arg-Cys (WRC) region. In addition, degradome sequencing analysis confirmed that four GRFs (GRF1, c56908.graph_c0; GRF4, c52862.graph_c0; GRF6, c39378.graph_c0 and GRF9, c54658.graph_c0) are hpo-miR396b targets that are regulated by specific cleavage at the binding site between the 10th and 11th nucleotides from the $5^{\prime}$ terminus of hpo-miR396b. Furthermore, quantitative real-time polymerase chain reaction (qRT-PCR) analysis showed that hpo-miR396b is down-regulated when confronted with drought stress (15\% polyethylene glycol, PEG), and its expression fluctuates under other abiotic stresses, i.e., low temperature $\left(4 \pm 1{ }^{\circ} \mathrm{C}\right)$, high temperature $\left(42 \pm 1^{\circ} \mathrm{C}\right), \mathrm{NaCl}(100 \mathrm{mM})$, and abscisic acid (ABA; $\left.0.38 \mathrm{mM}\right)$. Conversely, the expression of HpGRF6 showed the opposite trend to exposure to these abiotic stresses. Taken together, hpo-miR396b plays a regulatory role in the control of $H p G R F 6$, which might influence the abiotic stress response of pitaya. This is the first documentation of this role in pitaya and improves the understanding of the molecular mechanisms underlying the tolerance to drought stress in this fruit.
\end{abstract}

Keywords: pitaya; miR396b; phylogenetic analyses; HpGRF6; abiotic stress

\section{Introduction}

miRNAs are endogenous, single-strand, non-coding, small-molecular-weight RNAs of about 20 nucleotides (nt) in length, whose precursors are characterized by a stem loop structure [1,2]. They are known to regulate gene expression at the post-transcriptional level through cleavage and/or the translational repression of mRNAs [3]. miRNAs may also cause epigenetic modifications, including DNA and histone methylation, to control their targets [4-6]. Available evidence also justifies the idea that miRNAs are highly conserved, temporally and tissue-specifically expressed, and lead 
to the regulation of many biological processes, including those involved in growth, development, and metabolism, as well as abiotic and biotic stress responses in plants $[7,8]$. The post-transcriptional regulation of plant miRNAs to their targets is the main regulator of their function [9-11]. Thus, elucidation of the expression patterns of miRNAs and their corresponding targets at specific growth stages or in certain growth environments is of great significance for understanding their function [12].

Previous studies have demonstrated that in Medicago truncatula, miR398 and miR408 are induced by drought stress; conversely, the expression levels of the targets Copper superoxide dismutase 1 (CSD1) and Cytochrome coxidase subunit $\mathrm{Vb}(\mathrm{COX} 5 b)$ decrease significantly under such conditions [13]. The expression of the miR169 is inhibited by low nitrogen levels in Arabidopsis thaliana, and its target Nuclear transcription factor Yalpha (NFYA), which is part of a network that regulates nitrogen metabolism in combination with Nitrate transporters1.1 (AtNRT1.1) and AtNRT2.1 in A. thaliana, was up-regulated [14]. More recently, it was found that miR396 might regulate cell proliferation and differentiation by targeting growth-regulating factors (GRFs), thereby affecting growth and development and increasing a plant's stress tolerance [15].

GRF1, which was first discovered in Oryza sativa (Os-GRF1), is a gibberellin-regulated transcription factor that was expressed in Arabidopsis, and the stem elongation of the transformed plants was greatly inhibited [16]. Subsequently, nine members of the GRF family were discovered in $A$. thaliana, whose domains are similar to those of O. sativa GRFs [17]. In general, the Gln-Leu-Gln (QLQ) and Trp-Arg-Cys (WRC) motifs are conserved in the N-terminals of GRF genes. The QLQ domain can affect the expression of target genes bearing the QLQ domain binding sequence, and the WRC region contains a nuclear localization signal and a DNA binding region [18]. In 2004, the miR396 family was discovered by high-throughput sequencing (Illumina) of $A$. thaliana, and six AtGRF members were confirmed to be targets of ath-miR396 by $5^{\prime}$-Rapid amplification of cDNA ends (5'-RACE) $[19,20]$. Various studies have proven that the regulation of GRFs by miR396 plays an important role in plant growth and development and involves a variety of stress responses [21].

Pitaya (Hylocereus polyrhizus), belonging to the family Cactaceae, is an economical and nutritional fruit cultivated in tropical and subtropical regions, that is characterized by its high tolerance to drought stress $[22,23]$. Unfortunately, there are some limitations in its yield potential, namely drought and other adverse environments constrain its growth and development. Recently, the molecular response of pitaya to drought and salt stress at the transcriptomic level was documented [24,25]; however, the roles of miRNAs in this response have not yet been deciphered.

Previously, small RNA-seq, RNA-seq, and degradome-seq were applied in pitaya under exposure to drought stress, from which hpo-miR396b, whose target is HpGRF6, was found to be differentially expressed under drought stress. To unravel the roles of miR396b in response to abiotic stresses, in the current study, the hairpin sequence of $h p o-m i R 396 b$ and its target $H p G R F 6$ were isolated from pitaya. Supported by degradome sequencing, HpGRF6 was found to be sliced by hpo-miR396b at specific sites. Subsequently, the expression levels of $h p o-m i R 396 b$ and its target HpGRF6 under various stresses were determined. The results generated herein may further elucidate the roles of miR396b in plants' adaptation to abiotic stresses.

\section{Results}

\subsection{Cloning and Sequence Analysis of miR396b in Pitaya}

The expected band at about $240 \mathrm{bp}$ was observed by $2 \%$ agarose gel electrophoresis (Figure 1A), which is based on the stem-loop structure of hpo-miR396b. The sequencing result showed that the complete hairpin sequence was successfully cloned (130 bp). The alignment result showed that a similarity between the cloned hairpin and corresponding unigene of $100 \%$ (Figure 1B). 


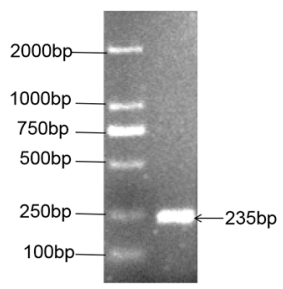

(A)

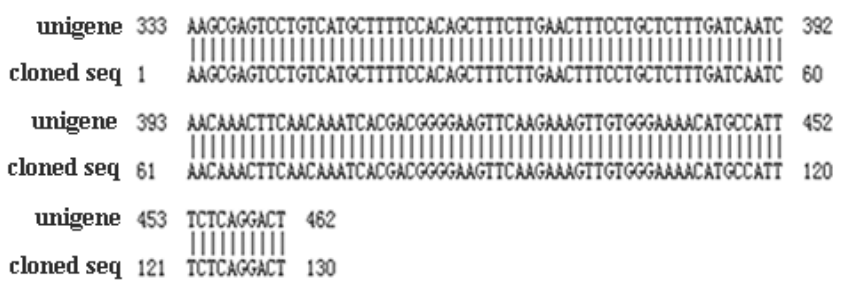

(B)

Figure 1. Cloning and sequence analysis of pitaya hairpin sequence MIR396b: (A) electrophoresis of cloned hpo-miR396b precursor; (B) alignment of the clone with the transcriptome.

The RNA fold analysis of the hairpin sequence revealed that it forms a typical stem-loop structure with hpo-miR396b and hpo-miR396b* located in the two opposite arms (shown by the red and purple line in Figure 2A). The hpo-miR396b sequence (5'-UUCCACAGCUUUCUUGAACUU- $3^{\prime}$ ) is located in the $5 \mathrm{p}$ arm of pitaya precursor miR396b (MIR396b). Additionally, the hpo-miR396b* read was uncovered from the RNA-seq data. Comparing the stem-loop structure of H. polyrhizus, A. thaliana, and Nicotiana tabacum MIR396b, the sequence of the two arm structure was found to be relatively conserved (Figure 2); however, their loops varied in sequence and minimum free energy (H. polyrhizus loop dG $=-4.20 \mathrm{kcal} / \mathrm{mol}$, A. thaliana loop dG $=-9.4 \mathrm{kcal} / \mathrm{mol}$, N. tabacum loop dG $=-0.7 \mathrm{kcal} / \mathrm{mol}$ ).

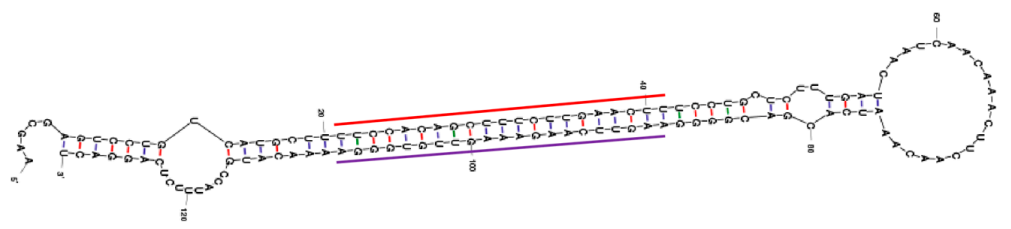

(A)

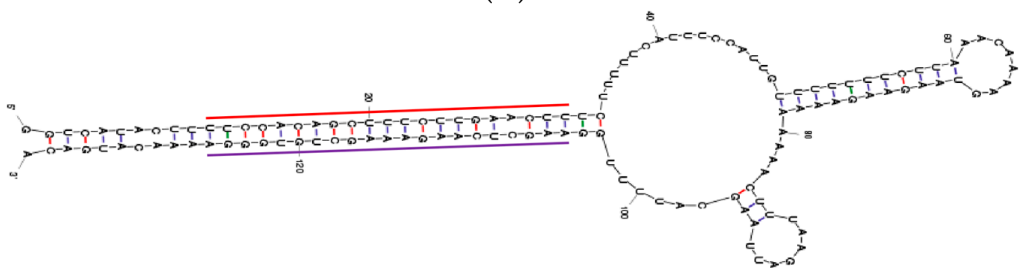

(B)

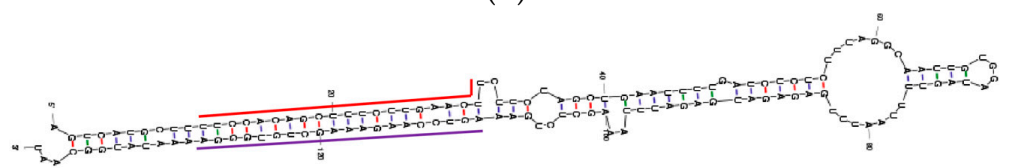

(C)

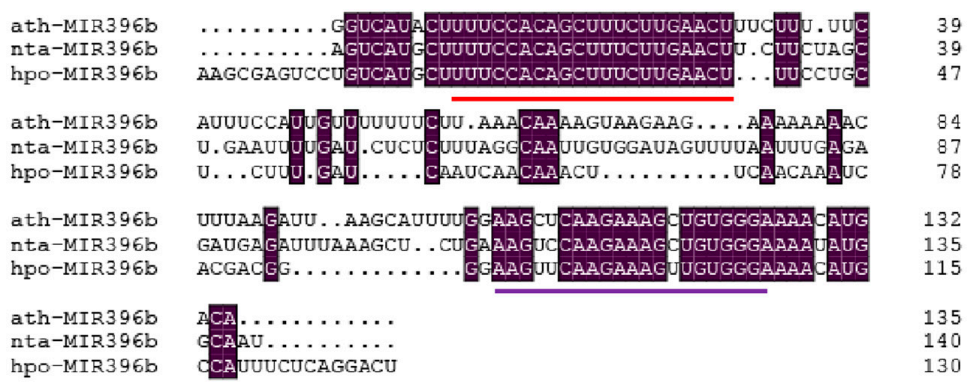

(D)

Figure 2. The comparison of the stem-loop structure of miR396b among three plant species: (A) H. polyrhizus (minimum free energy dG $=-55.80 \mathrm{kcal} / \mathrm{mol}$ ); (B) A. thaliana (minimum free energy $\mathrm{dG}=-43.59 \mathrm{kcal} / \mathrm{mol}$ ); (C) N. tabacum (minimum free energy dG $=-55.90 \mathrm{kcal} / \mathrm{mol}$ ); (D) Alignment sequence analysis of MIR396b from the three species. miR396b and $m i R 396 b^{*}$ are shown by the red and purple line in Figure 2. Nucleotides that are identical are highlighted in purple background. 


\subsection{Phylogenetic Analysis of Plants MIR396b}

The precursors of the miRNA genes are much longer than the mature miRNA molecule, and their nucleotide sequences vary within as well as between species. Therefore, phylogenetic analysis of the precursor sequences of a MIRNA family may reveal the true evolutionary relationships between its MIRNA genes. Thirty-four species of plant MIR396b, including pitaya, were identified in this study through phylogenetic analysis. Based on the phylogenetic tree (Figure 3), the whole system was divided into three branches, and the monocotyledonous Vriesea carinata, Aegilops tauschii, and Brachypodium distachyon were clustered into a branch. The gymnosperm plant of Picea abies was separately clustered into a single branch, whereas the monocotyledonous Zea mays, Sorghum bicolor, Asparagus officinalis, and Oryza sativa and dicotyledons including pitaya MIR396b were in another branch. The pitaya and dicotyledonous plants were more closely clustered than the plant of monocotyledonous and gymnosperm, and the MIR396b sequences of members of the Brassicaceae, Poaceae, and Solanaceae families and other plants were clustered together. Plant MIR396b has a more recent evolutionary relationship in the family, but there were also a few species with intra-family plant aggregation, such as legume plants, like Glycine max and Medicago truncatula. The clustering of pitaya and the dicotyledonous species was more scattered, which further demonstrated that, in addition to species differences, there are other factors that influence the formation of MIR396b, also indicating that the origin of the pitaya MIR396b is quite special.

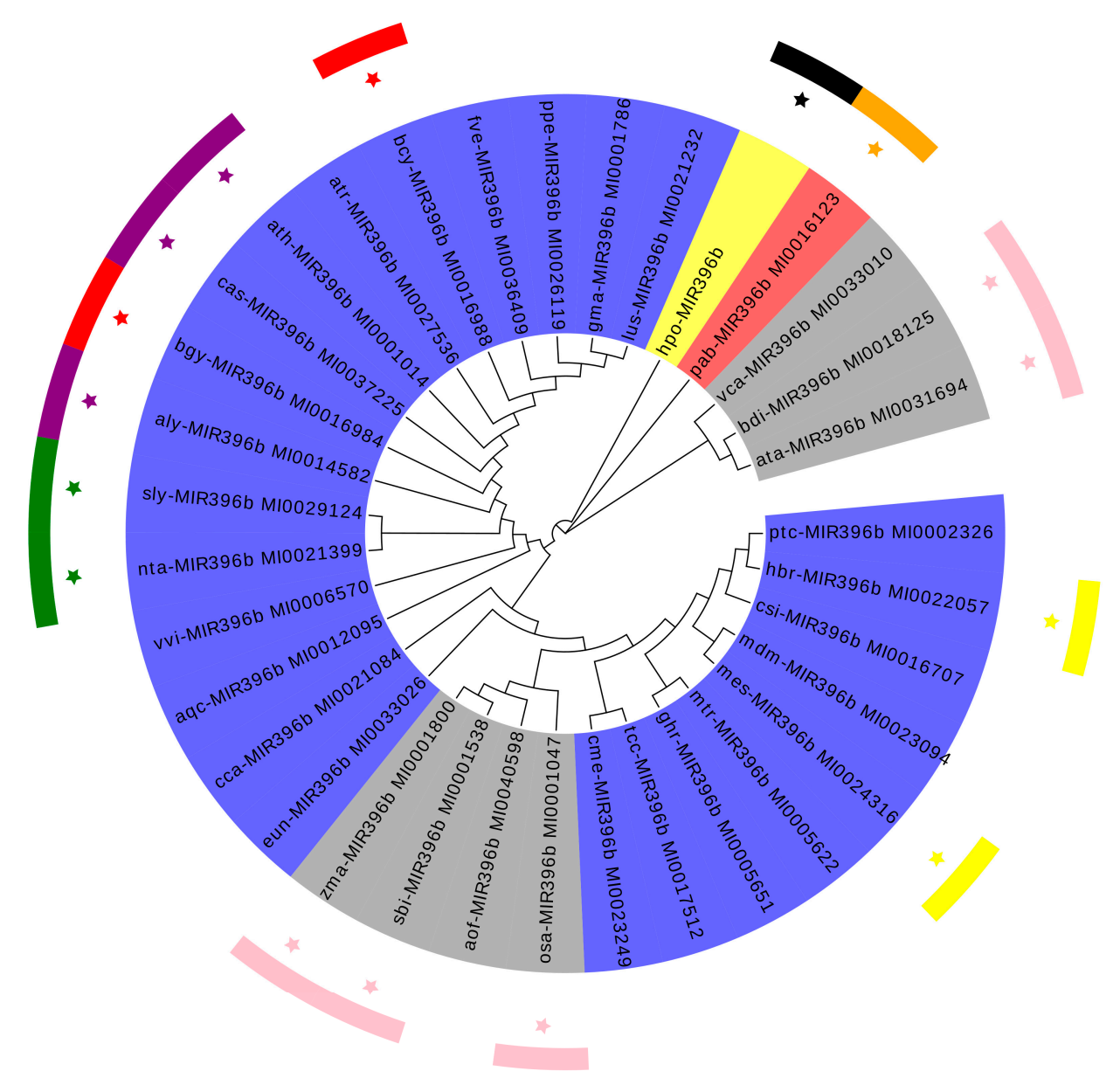

Figure 3. Phylogenetic tree of MIR396b from thirty-four plant species. MEGA (Tokyo Metropolitan University, Tokyo, Japan, Version 6.0) was used to build the neighbor-joining (NJ) tree with 1000 bootstrap replicates. Different colors indicate different classes of plants. Blue, gray, and red represent the plant dicotyledons, monocotyledonous, and gymnosperm, respectively. H. polyrhizus is represented by yellow. In addition, different star-line colors indicate different families of plants. 


\subsection{Conservation Analysis of Plants miR396b}

Alignment between miR396b sequence of twelve plant species including hpo-miR396b analyzed from the miRbase database (Release 22.1) (Figure 4A), and the mature sequence of hpo-miR396b was consistent with most of the other plants' miR396b. The substitution analysis of the $5^{\prime}$ product of miR396b showed that its bases were highly conserved (Figure 4B), indicating that it is of great importance and is highly conserved during evolution.

$$
\begin{aligned}
& \text { hpo-miR396b } \\
& \text { ath-miR396b } \\
& \text { osa-miR396b } \\
& \text { sbi-miR396b } \\
& \text { gma-miR396b } \\
& \text { zma-miR396b } \\
& \text { mtr-miR396b } \\
& \text { ghr-miR396b } \\
& \text { pab-miR396b } \\
& \text { cca-miR396b } \\
& \text { nta-miR396b } \\
& \text { sly-miR396b }
\end{aligned}
$$
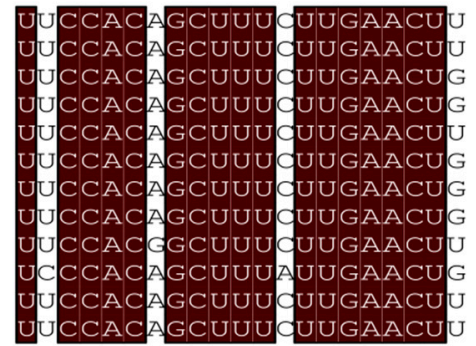

(A)

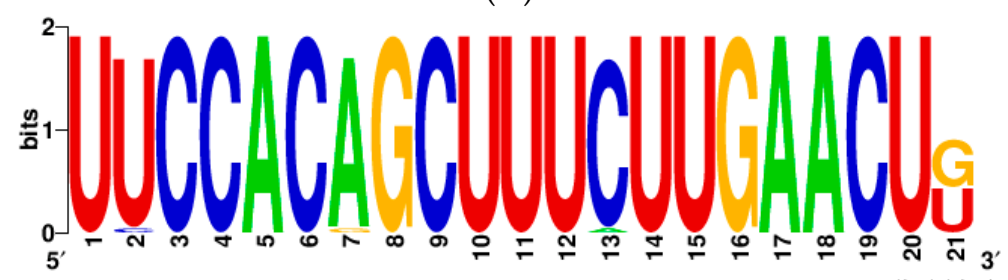

(B)

Figure 4. Conserved nucleotide sequence analysis of plant miR396b: (A) alignment of the logo sequence of miR396b from twelve plant species whose names are H. polyrhizus (hpo-miR396b), A. thaliana (ath-miR396b), O. sativa (osa-miR396b), Sorghum bicolor (sbi-miR396b), Glycine max (gma-miR396b), Zea mays (zma-miR396b), Medicago truncatula (mtr-miR396b), Gossypium hirsutum (ghr-miR396b), Picea abies (pab-miR396b), Cynara cardunculus (cca-miR396b), Nicotiana tabacum (nta-miR396b), and Solanum lycopersicum (sly-miR396b), respectively. Nucleotides that are identical are highlighted in dark red background; (B) the logo sequence of miR396b, and the height of the letter at each position represents the degree of conservation.

\subsection{Prediction of Hpo-miR396b Target Genes}

To date, all miR396-targeted genes identified from $A$. thaliana have been found to belong to the GRF gene family. To identify hpo-miR396b targets in pitaya, pitaya mRNA sequences were searched, and complementary sequences to the mature hpo-miR396b sequences were found based on the near-perfect complementarity principle. The number of predicted targets of hpo-miR396b is 19, of which 17 have been annotated (Appendix A Table A1). The preliminary annotations suggest that hpo-miR396b is involved in a variety of biological processes such as transcriptional regulation, substance metabolism, and stress response. Supported by degradome sequencing (SRA: SRR8767413), four GRFs (GRF1, c56908.graph_c0; GRF4, c52862.graph_c0; GRF6, c39378.graph_c0 and GRF9, c54658.graph_c0) were shown to be hpo-miR396b targets that are regulated by specific cleavage at the binding site between the 10th and the 11th nucleotides from the $5^{\prime}$ terminus of hpo-miR396b (Figure 5). 


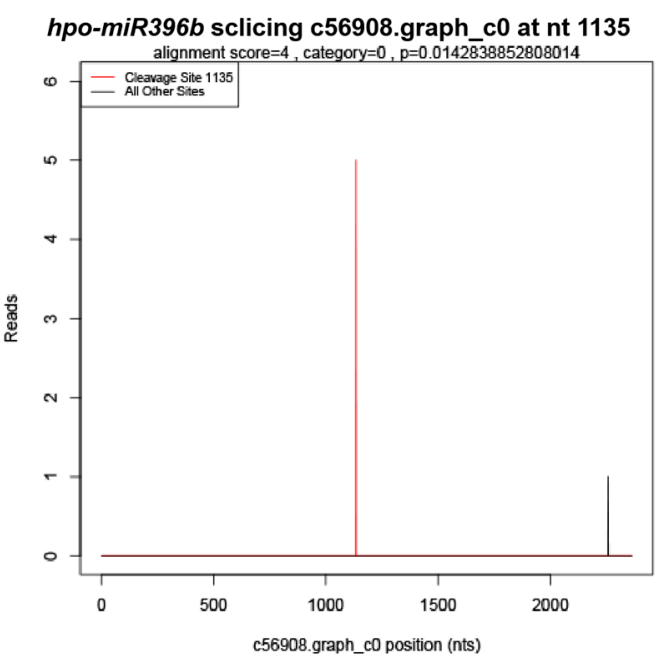

Growth-Regulating Factor 1

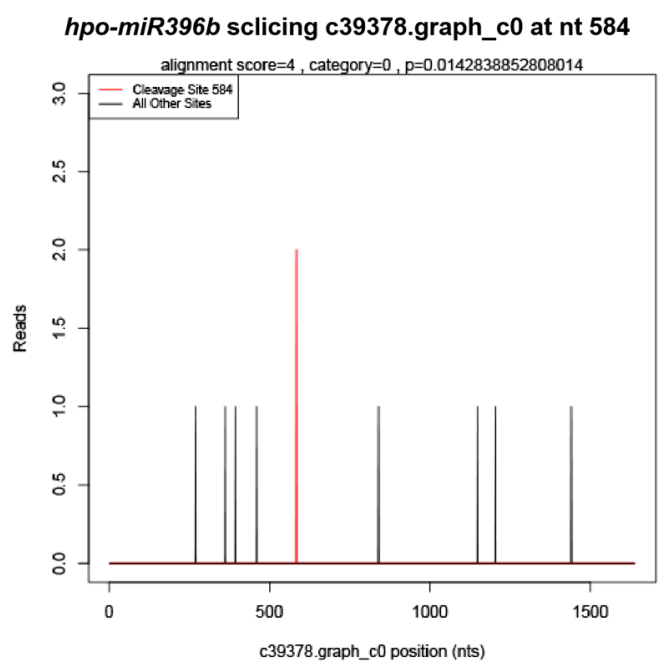

Growth-Regulating Factor 6

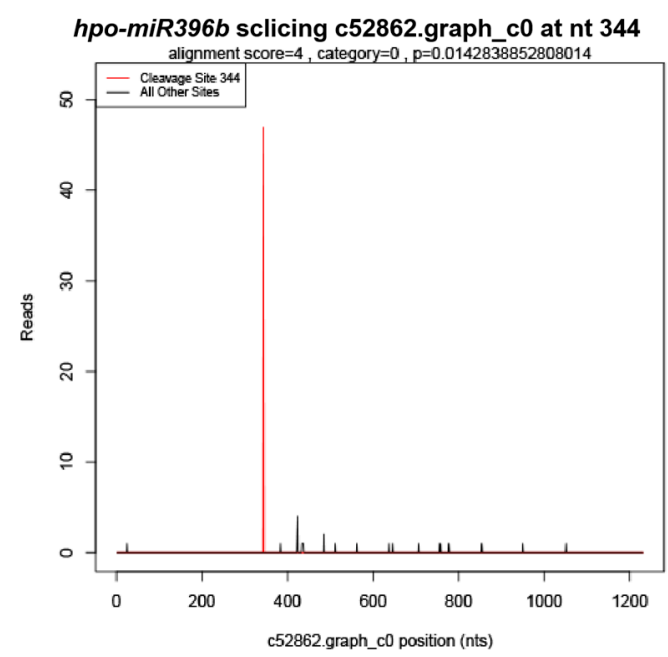

Growth-Regulating Factor 4

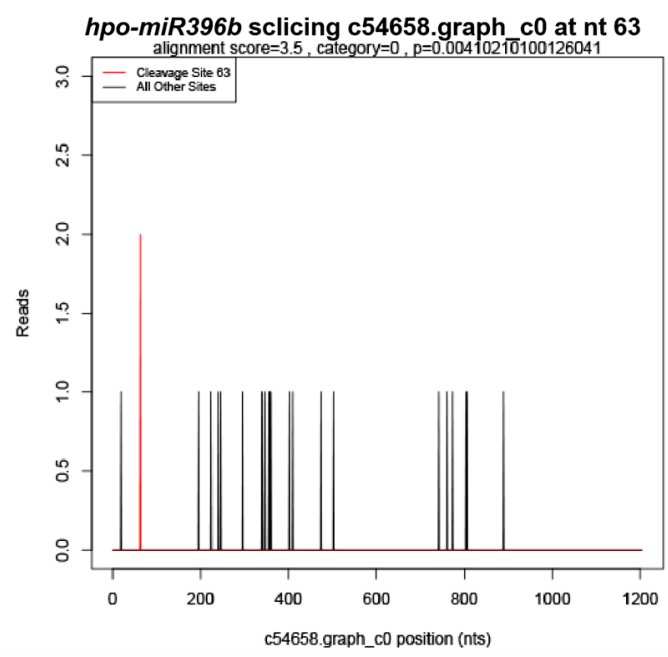

Growth-Regulating Factor 9

Figure 5. Target plot (t-plot) of target genes of the growth regulating factor (GRF) of hpo-miR396b gained by degradome sequencing. The red lines of $t$-plots indicate that the specific cleavage site. The $X$ axis indicates the unigene. The $y$ axis indicates the raw reads.

\subsection{Cloning and Structure Analysis of HpGRF6}

The open reading frame (ORF) of target gene HpGRF6 (c39378.graph_c0) was amplified. The expected band at about $1200 \mathrm{bp}$ was detected by $2 \%$ agarose gel electrophoresis (Figure 6A). The sequencing result showed that the cloned sequence is $1154 \mathrm{bp}$ and contains $1119 \mathrm{bp}$ ORF encoding a polypeptide chain of 372 amino acids (GeneBank: MK625692). Smart software predicted the domain and demonstrated its similarity to GRF genes in other plants, whose conserved domains are QLQ and WRC. The sequence analysis indicated that the interaction site in miR396b-HpGRF6 is located in the WRC domain of the coding region 'CCGUUCAAGAAAGCCUGUGGAA', coding the conserved "RSRKPVE" amino acid sequence (Figure 6B). BoxShade was used to compare the transcription factor GRFs of H. polyrhizus, Chenopodium quinoa, and A. thaliana, and the similarities with C. quinoa and A. thaliana were $98 \%$ and $91 \%$ (Figure $6 \mathrm{C}$ ), respectively, indicating high conservation among the three GRFs. In addition, miR396 was shown to be conserved. 


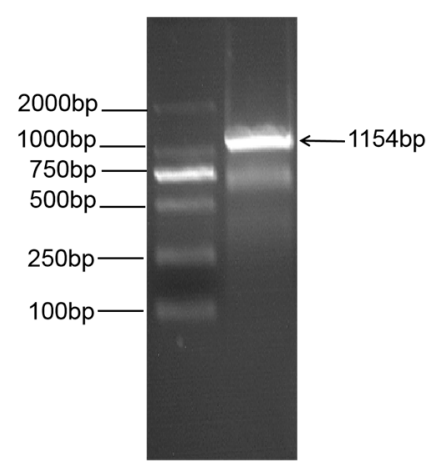

(A)

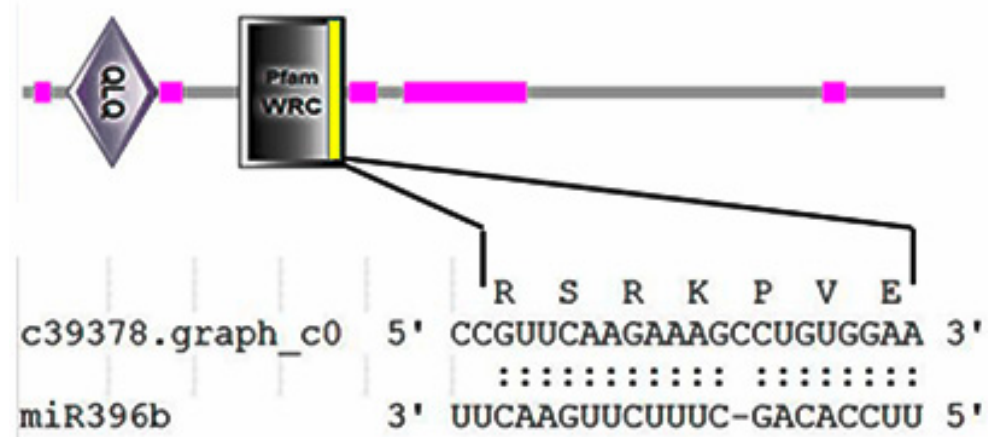

(B)

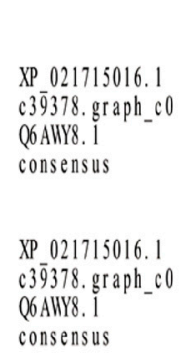

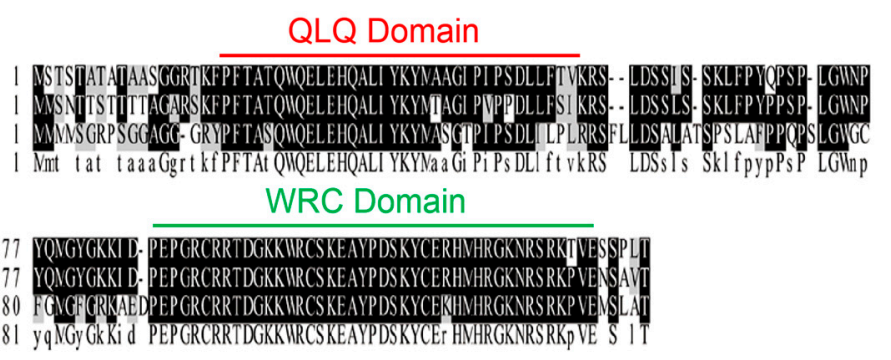

(C)

Figure 6. Cloning and sequence analysis of HpGRF6: (A) electrophoresis of cloned HpGRF6; (B) prediction of the conservative domain of HpGRF6, whose conserved domains are QLQ and WRC, and the double black points indicate matched base pairs; (C) amino acid sequence alignment of HpGRF6 with the conserved domains of other plant species. XP_021715016.1, Q6AWY8.1 and c39378.graph_c0 represent the plants C. quinoa, A. thaliana, and H. polyrhizus, respectively. Residues that are identical are highlighted in black and different residues are highlighted in grey background.

\subsection{Subcellular Localization of HpGRF6 Protein}

The ORF of HpGRF6 without a stop codon was inserted into the pBWA(V)HS-GLosgfp vector to express the pBWA(V)HS-HpGRF6-GLosgfp (control green fluorescence protein (GFP)) recombinant protein, and the constructed plasmid vector was transformed into tobacco. A fluorescence signal was found in the nuclear region of epidermal cells (Figure 7), justifying that the WRC region of the HpGRF6 gene has the same nuclear localization signal as GRF in other species.

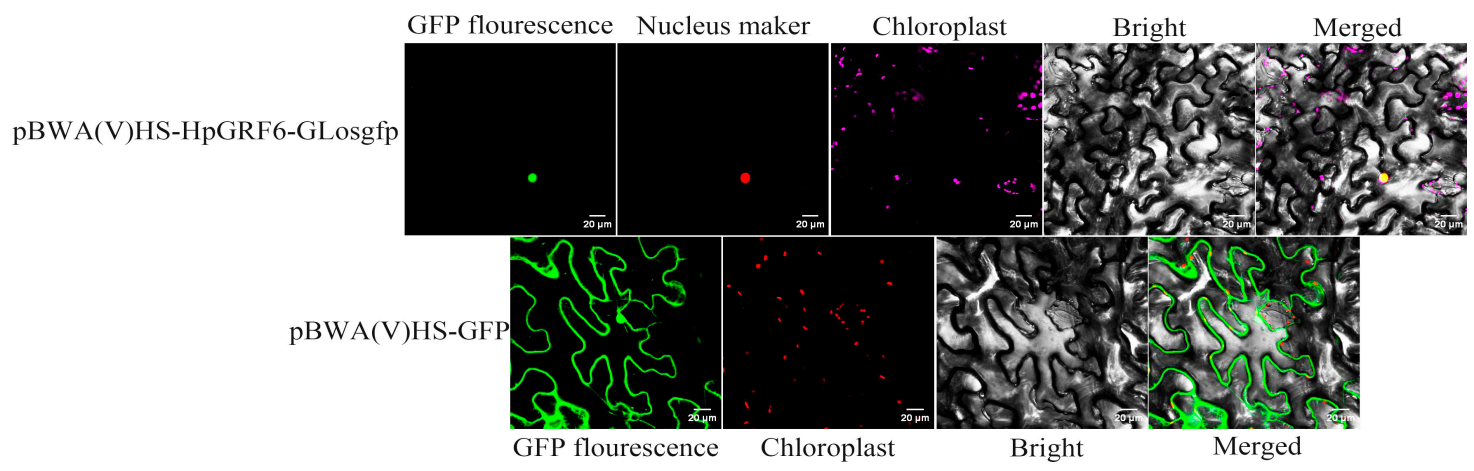

Figure 7. Subcellular localization of HpGRF6 in tobacco leaves. The construct of HpGRF6 fused with the N-terminal of green fluorescence protein (GFP; pBWA(V)HS-HpGRF6-GLosgfp) was co-infiltrated with pBWA(V)HS-GFP into tobacco leaves. The co-infiltrated leaves were photographed after 3 days. Note: GFP fluorescence (green), nucleus fluorescence (red), merged images (yellow), and bright-field chloroplast (rose red) images are shown. Scale bar $=20 \mu \mathrm{m}$. 


\subsection{Expression of hpo-miR396b and HpGRF6 during Exposure to Abiotic Stresses}

In order to check the negative correlation between hpo-miR396b and GRF, we analyzed the expression of hpo-miR396b and its target gene HpGRF6 following exposure to treatments with polyethylene glycol (PEG), high/low temperature, $\mathrm{NaCl}$, and abscisic acid (ABA). The expression of hpo-miR396b was obviously down-regulated under drought stress, obtaining a minimum level $(-37 \%)$ after $20 \mathrm{~h}$ (Figure 8A), while the expression of HpGRF6 showed the opposite trend, and reached a maximum (+5.4-fold) at $20 \mathrm{~h}$ after treatment with 15\% PEG. hpo-miR396b and HpGRF6 expression fluctuated under both high and low temperatures, reaching the highest point at $8 \mathrm{~h}(p<0.01)$ after exposure to high-temperature stress (Figure $8 \mathrm{~B}$ ); however, the expression of hpo-miR396b rapidly and transiently increased after exposure to low temperature for $2 \mathrm{~h}$ (Figure $8 \mathrm{C}$ ), and then decreased at $8 \mathrm{~h}$, reaching its lowest point $(p<0.05)$. We also analyzed the HpGRF6 gene under the same conditions; its expression showed the exact opposite trends to hpo-miR396b (Figure 8C). After $20 \mathrm{~h}$ of treatment with $\mathrm{NaCl}(300 \mathrm{mM})$, hpo-miR396b was responsive to salt stresses and reached its maximum expression at $2 \mathrm{~h}$, before declining until $20 \mathrm{~h}$ (Figure 8D). Hpo-miR396b was also involved in the response to ABA stresses, but the differences did not reach a significant level (Figure 8E). Conversely, under both $\mathrm{NaCl}$ and ABA stresses, HpGRF6 showed a trend that was opposite to that of hpo-miR396b, suggesting that HpGRF6 is involved in slat and phytohormone ABA stresses. Moreover, the expression of hpo-miR396b and HpGRF6 showed opposite trends under exposure to these abiotic stresses, suggesting that HpGRF6 is the hpo-miR396b-targeted gene, demonstrating the crucial role it may play in the plant stress response as well as in plant defense.

To understand the spatio-temporal expression of miR396b, quantitative real-time polymerase chain reaction (qRT-PCR) was carried out and the results showed that hpo-miR396b is expressed differentially in pitaya tissues (Figure 8F). Using the stem as a control, expression was barely detected in the root, while it was about 26 times higher in the fruit, reaching an extremely significant level $(p<0.01)$.

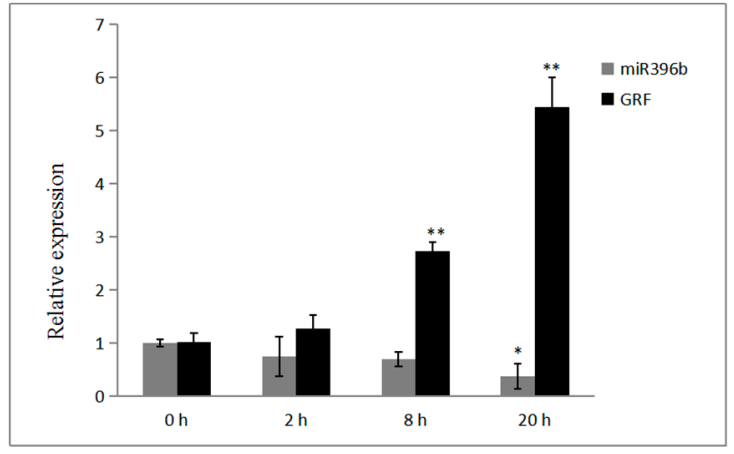

(A) PEG

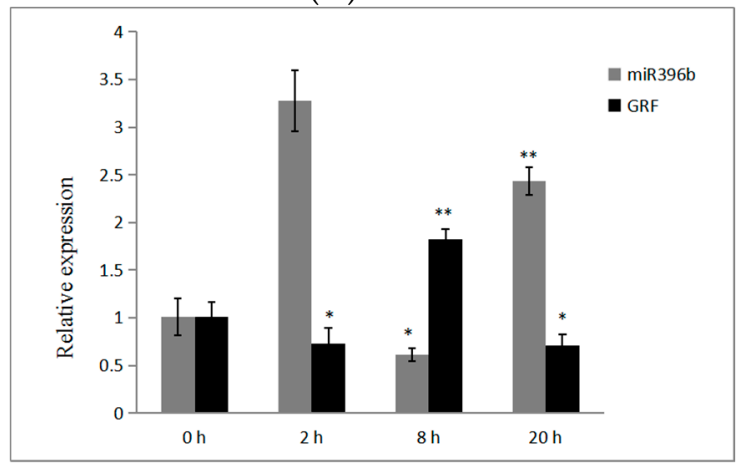

(C) Low temperature

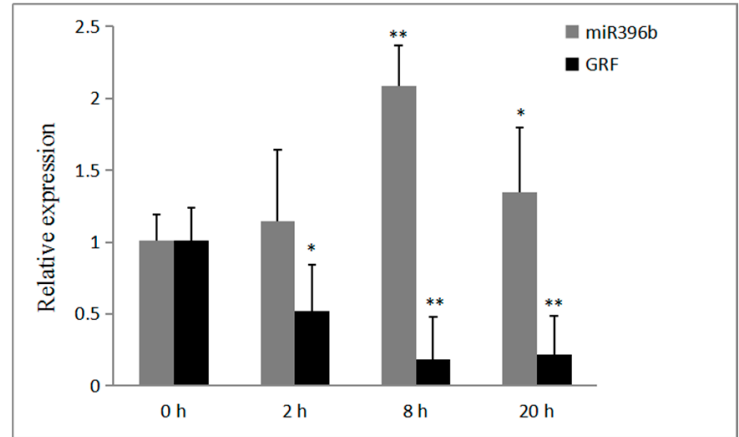

(B) High temperature

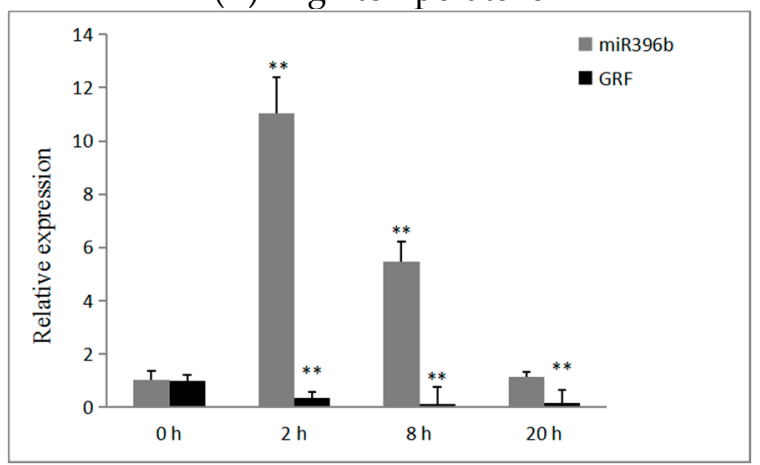

(D) $\mathrm{NaCl}$

Figure 8. Cont. 


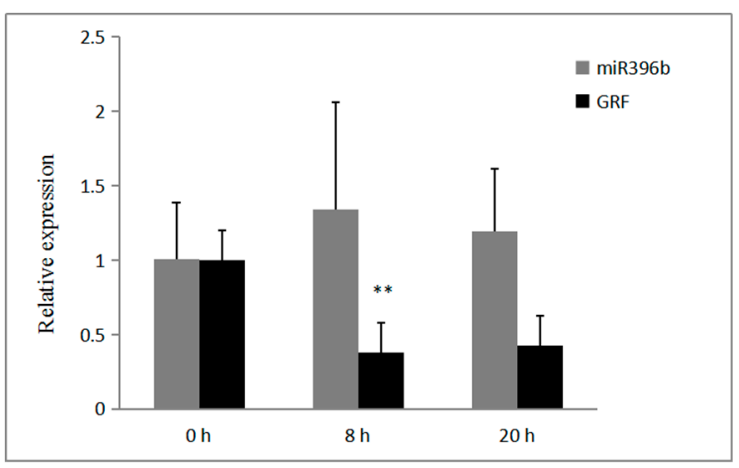

(E) ABA

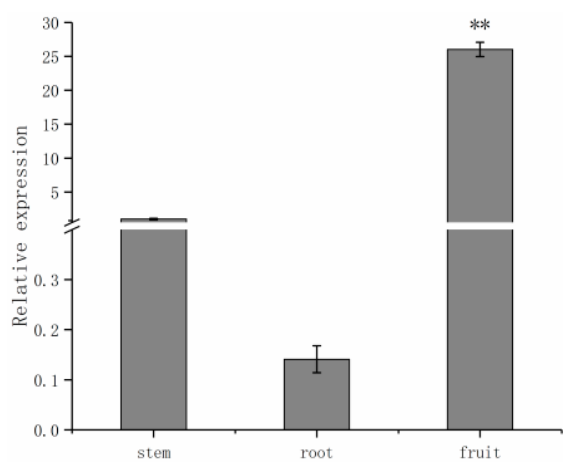

(F) Different tissue

Figure 8. Expression patterns of hpo-miR396b and the target gene HpGRF6 under exposure to different treatments: (A-E) expression of hpo-miR396b and HpGRF6 induced by polyethylene glycol (15\% PEG-8000), $42 \pm 1{ }^{\circ} \mathrm{C}, 4 \pm 1{ }^{\circ} \mathrm{C}, \mathrm{NaCl}(100 \mathrm{mM})$ and abscisic acid (ABA; $\left.0.38 \mathrm{mM}\right)$; (F) expression of hpo-miR396b in different tissues. All data were analyzed by two-way ANOVA, and followed by Duncan's multiple range test. "*” indicates a significant difference at the level of $p<0.05$. "*** indicates a significant difference at the level of $p<0.01$.

\section{Discussion}

\subsection{Evolution and Conservation Analysis of Plants miR396b}

miRNA genes were widely distributed in plants such as trees, herbage, or even bryophytes, etc. Three hypotheses had been proposed to explain their origins, of which the first was that the new miRNA gene originated from a duplication of genetic elements such as miRNA and protein-coding genes, and the second was that terminal inverted repeats of transposable elements became miRNA genes [26-28]. During the past decade, some research suggested that most miRNAs originated from random hairpin (stem-loop) structures, which was the third hypotheses $[29,30]$, because there are hundreds of thousands hairpin structures in the genomes of higher organisms and some of which may become miRNA genes [31]. Additionally, lots of miRNA genes identified by these efforts were not related to the phylogeny but rather to the tissue type and developmental stages of plants. In liverwort, 428 miRNAs had been obtained from Pellia endiviifolia [32]; however, only 129 were available from Marchantia polymorpha [33]. Interestingly, our results show that there was a typical stem-loop structure in MIR396b of pitaya, indicating that it might become miR396b subsequently. No MIR396b in liverworts or algae was found in the miRBase (Release 22.1), which might be ascribed to the tissue- or species-specific expression. To examine the conservation of miR396b genes, alignment of miR396b sequences from twelve plant species was carried out (Figure 4A). The sequence of hpo-miR396b was identical to A. thaliana, N. tabacum, and G. max, etc., and showed one base difference with Picea abies. The nucleotide substitution analysis for the $5^{\prime}$ product of miR396b demonstrated that its sequence was highly conserved (Figure 4B).

\subsection{Target Genes of miR396b}

Unlike functional genes, miRNA itself does not translate into proteins; however, it may regulate target genes. Therefore, to better unravel the function of miRNA, we investigated the target genes of its action. At present, degradome sequencing has been used to identify miRNA cleavage sites [34], because miRNAs can cause the endonucleolytic cleavage of mRNA by extensive and often perfect complementarity to mRNAs [35]. Degradome sequencing has revealed many known and novel plant miRNA targets [36,37]. Recently, it has also been applied to identify A. thaliana [38], Z. mays [39], and Gossypium hirsutum [40], among other miRNA-derived cleavages. Shamimuzzaman (2012) obtained 183 target genes from 53 conserved miRNAs by analyzing the soybean seed degradome 
sequencing library [41]. Potential target genes for some conserved and novel miRNAs were identified by degradome sequencing in peanuts [42].

To date, there has been no research into the cactus family's miRNA or the understanding of its target genes. Recently, investigations have shown that miR396-mediated GRFs may play a role in coordinating plant growth through defense signaling and stress responses [43,44]. In addition, the basic helix-loop-helix (bHLH) transcription factor 74 gene (bHLH74) was identified as the target of miR396 that acts as a regulator for root growth in Arabidopsis seedlings [45,46], but bHLH74 homologs with a miR396 target site were only detected in the sister families Brassicaceae and Cleomaceae [47]. In the present study, a detailed predictive analysis of the hpo-miR396b target genes was carried out. Based on the findings herein, the main target genes of hpo-miR396b are also members of the HpGRF family. Supported by degradome sequencing, four of the GRFs were shown to be hpo-miR396b targets, and they are all regulated by specific cleavage at the binding site between the 'CCGUUCAAGAA' and the 'AGCCUGUGGAA' nucleotides from the 5' terminus of $H p G R F s$, which is consistent with the cleavage site reported in tea [48]. It was further shown that hpo-miR396b can cleave the targets at the transcriptional level to regulate their expression.

\subsection{Tissue-Specific and Abiotic Stress Response of miR396 in Plant}

As a conserved and well-studied miRNA family in terrestrial plants, miR396 is known to be expressed in different plant tissues. Rodriguez et al. (2010) and Bao et al. (2014) detected the expression of miR396 in the leaves and roots of Arabidopsis [15,46], and Baucher et al. (2012) found that miR396 is expressed in the floral organs of poplar [49]. Available evidence also suggests that mtr-miR396a and $m t r-m i R 396 b$ genes are highly expressed in the tips of roots and display distinct expression profiles during lateral root and nodule development in Medicago truncatula [50]. In the present study, the expression of hpo-miR396b in pitaya fruit was shown to be significantly higher than that in other organs, indicating that the expression pattern of hpo-miR396 is tissue-specific.

Unlike animals, which are capable of escaping stressful conditions by moving away, plants must cope with stress directly at the place where the seed has germinated. As a consequence, the growth of plants is often influenced by stress. A great deal of research has shown that the activation of stress-related genes increases a plant's tolerance to stress [51,52]. In recent studies, it was demonstrated that miR396 is involved in responses to a variety of biotic and abiotic stresses. Liu et al. found that transgenic miR396-overexpressing plants are more tolerant to drought than wild-type plants in Arabidopsis [53]. In particular, the AtGRF3 transgene yielded an increase in leaf size under mild drought stress and showed enhanced resistance to certain plant pathogens [54]. Further analysis revealed that $S p-m i R 396 a-5 p$ transcription levels are up-regulated under salt and drought stresses, and additionally, the expression of $S p-m i R 396 a-5 p$ is down-regulated under pathogen-related biotic stress [55], and the relevant link between salt and alkali stress of osa-miR396c in rice was established by Gao et al. [56]. Recent clues also revealed that homeostasis in the miR396-GRF regulatory network was essential for productive Heterodera glycines infections in soybean [57]. Considering all evidence, it is clear that miR396-targeted GRFs play important roles in the response to biotic and abiotic stresses, including drought, salt, alkali, and UV-B radiation [58], among others. Interestingly, our results showed that the expression of hpo-miR396b and HpGRF6 have opposite trends, which reach different levels during responses to abiotic stresses in pitaya. This might be helpful for further elucidating the roles of miR396b in plants' adaptation to stress tolerance. For the first time, miRNA and mRNA expression were analyzed during the osmotic stress response in pitaya, giving new insight into the regulation of pitaya's adaptation to abiotic stress tolerance. 


\section{Materials and Methods}

\subsection{Plant Material and Stress Treatment}

Given that the stem is the primary organ of pitaya seedlings, it was used to examine differential expression of $m i R 396 b$ and its target in response to abiotic stresses. The stem of pitaya (H. polyrhizus) was obtained from the research greenhouse, Ministry of Education, Institute of Agro-Bioengineering, Guizhou University. To verify the expression of the hpo-miR396b' targeted HpGRF6 gene under various abiotic stresses and phytohormone treatments, selected aseptic seedlings of pitaya were cultured in 1/2 MS liquid medium at a day/night temperature of $25 \pm 1 / 20 \pm 1{ }^{\circ} \mathrm{C}$ inside a greenhouse, with $50-60 \%$ relative humidity. After 1 week, the aseptic seedlings were transferred into 1/2 MS liquid medium containing 15\% PEG-8000/100 mM NaCl solution and exposed to artificially induced drought/salt stress treatments for $0,2,8$, and $20 \mathrm{~h}$. Some of the seedlings were transferred into $1 / 2 \mathrm{MS}$ liquid medium containing ABA $(0.38 \mathrm{mM})$, and exposed to artificially induced hormone stress treatments for 0,8 , and $20 \mathrm{~h}$. Untreated material was used as a control. For cold/heat stress, seedlings were transferred to the artificial climate incubator for $4 \pm 1{ }^{\circ} \mathrm{C} / 42 \pm 1{ }^{\circ} \mathrm{C}$ treatments for $0,2,8$, and $20 \mathrm{~h}$, with normal-temperature $\left(25 \pm 1^{\circ} \mathrm{C}\right)$ material as a control.

To investigate the tissue-specific expression of miR396b, samples representing the tissues of the stem, root and fruit of pitaya (H. polyrhizus), were collected according to the designated quantitative expression level analysis, which were provided by the Institute of Fruit Trees, Guizhou Province Academy of Agricultural Sciences.

\subsection{Prediction of Hpo-miR396b Target Genes in Pitaya}

The sequences of hpo-miR396b and mRNA were obtained from our previous small RNA library, and RNA-Seq were constructed from the stems of pitaya conducted with drought stress high-throughput sequencing and input into psRNATarget (http://plantgrn.noble.org/psRNATarget/, 2017 Release) and Targetfinder (http://targetfinder.org/, 2010 Release) to search for targets in pitaya [59,60]. Its library maximum expectation of $\leq 4.0$ was selected for target prediction. We took the intersection of the software psRNATarget and Targetfinder predictions as the final result, supported by the degradome sequencing of pitaya in drought stress to identify the predicted targets.

\subsection{Gene Cloning and Sequence Analysis}

To form the gene clone of hairpin sequence of pitaya miR396b by PCR, whose primers (Appendix A Table A2) were designed based on the small RNA sequences, DNA was isolated using DNAsecure Plant Kit (Tiangen, Beijing, China) at a total volume of $20 \mu \mathrm{L}$ containing $10 \mu \mathrm{L}$ of Taq PCR Master Mix (Tiangen), $1 \mu \mathrm{L}$ of each primer, $1 \mu \mathrm{L}$ gDNA, and $7 \mu \mathrm{L}$ of $\mathrm{ddH}_{2} \mathrm{O}$. PCR conditions were as follows: $95^{\circ} \mathrm{C}$ for $10 \mathrm{~min}$ followed by 35 cycles of $95^{\circ} \mathrm{C}$ for $30 \mathrm{~s}$ and $60^{\circ} \mathrm{C}$ for $1 \mathrm{~min}$. Obtained PCR products were resolved in $2 \%$ agarose gels, according to standard procedures. The target fragment was purified by TIANgel Midi Purification Kit (Tiangen) and then it was cloned into pMD19-T (Takara, Dalian, China), yielding the plasmid pMD19-T-miR396b. Next, the ligated vector was transformed into DH5 $\alpha$ competent cells, which were cultured overnight in LB medium containing Amp, and positive clones were selected for sequencing.

Based on the results of the prediction and degradome sequencing, HpGRF6 (c39378.graph_c0) was selected to design the primer (Appendix A Table A2) containing the full length of ORF. RNA was isolated using the miRcute miRNA Extraction and Isolation Kit (Tiangen). cDNA was synthesized by the RevertAid First Strand cDNA Synthesis Kit (Thermo Scientific, Waltham, MA, USA), where $2 \mu \mathrm{g}$ of total RNA was reverse-transcribed in a $20 \mu \mathrm{L}$ reaction containing oligo-dT primer $1 \mu \mathrm{L}$, Random Hexamer Primer $1 \mu \mathrm{L}, 5 \times$ Reaction Buffer $4 \mu \mathrm{L}, 10 \mu \mathrm{M}$ dNTPs (mix) $2 \mu \mathrm{L}$, RiboLock RNase Inhibitor $1 \mu \mathrm{L}$, and ReverAid M-MuLV RT $1 \mu \mathrm{L}$, at $42^{\circ} \mathrm{C}$ for $60 \mathrm{~min}$, and heat inactivation of the enzyme was performed at $70{ }^{\circ} \mathrm{C}$ for $5 \mathrm{~min}$. The method followed was the same as that used for the cloning of the hairpin hpo-miR396b sequence. 


\subsection{Bioinformatics Analysis}

Both mature and hairpin (precursor) sequences of plant miR396b were downloaded from the miRBase sequence database (http://www.mirbase.org, Release 22.1). Conserved amino acid sequences were determined by multiple sequence alignment (MSA) using Clustal X (Version 1.81) and BoxShade (http://sourceforge.net/projects/boxshade, version 1.8) tools. The RNAfold Web Server (http://unafold. rna.albany.edu, version 3.4) predicted the secondary structure of hairpin sequence hpo-miR396b. A phylogenetic tree of plant MIR396b was generated by MEGA (Tokyo Metropolitan University, Tokyo, Japan, version 6.0) using the neighbor-joining method. The conservation of plant miR396b was analyzed by Weblogo (http://weblogo.berkeley.edu/, version 2.8). The ORF of HpGRF6 was analyzed by NCBI (https://www.ncbi.nlm.nih.gov/orffinder/, National Center for Biotechnology Information, U.S. National Library of Medicine), and SMART software (http://smart.embl-heidelberg.de/, version 7.0) predicted the conserved domain. Subcellular localization of $H p G R F 6$ protein was predicted using TargetP (http://www.cbs.dtu.dk/services/TargetP/, version 1.1)

\subsection{HpGRF6 Protein Subcellular Localization}

The subcellular localization expression of HpGRF6 protein was observed by the tobacco leaf transient transformation technique. The ORF without a stop codon of HpGRF6 (Appendix A Table A2) was inserted into the pBWA(V)HS-GLosgfp vector, which was provided by BIORUN Technologies company (Wuhan, China) to express pBWA(V)HS-HpGRF6-GLosgfp (control GFP) recombinant protein. In addition, transformation analysis was performed according to the transient transformation scheme of tobacco leaf epidermal cells [61]. Transfected genes of interest were observed under a confocal laser scanning microscope C2-ER, (Nikon, Tokyo, Japan) to determine the expression of GFP in tobacco cells.

\subsection{Quantitative Real-Time Polymerase Chain Reaction (qRT-PCR) Analysis}

For the qRT-PCR analysis of HpGRF6 and hpo-miR396b, total RNA was isolated using the miRcute miRNA Extraction and Isolation Kit (Tiangen), followed by the RNA quality and purity measurement by the NanoDrop 2000 (Thermo Scientific, Waltham, MA, USA). cDNA was synthesized by the RevertAid First Strand cDNA Synthesis Kit (Thermo Scientific). qRT-PCR was performed on the Real-Time PCR system (Applied Biosystems, Foster City, CA, USA) using the SYBR Green Master Mix, with no less than three independent biological replicates, each comprising three technical replicates. Each technical replicate was prepared in a total volume of $20 \mu \mathrm{L}$ containing $10 \mu \mathrm{L}$ of SYBR Green PCR Master Mix, $1 \mu \mathrm{L}$ of each primer, $2 \mu \mathrm{L}$ cDNA, and $6 \mu \mathrm{L}$ of $\mathrm{ddH}_{2} \mathrm{O}$. Stem-loop qRT-PCR for mature miR396b was conducted as described previously [62,63], with $U 6 / R P 40 S$ as the pitaya miR396b/HpGRF6 endogenous reference, respectively. The qRT-PCR conditions were as follows: $95^{\circ} \mathrm{C}$ for $5 \mathrm{~min}$ followed by 35 cycles of $95^{\circ} \mathrm{C}$ for $30 \mathrm{~s}$ and $60^{\circ} \mathrm{C}$ for $30 \mathrm{~s}$. The primers (Appendix A Table A2) were designed by Primer Premier 5.0.

\subsection{Statistical Analysis}

The preceding Section 4.6 qRT-PCR analysis, all experiments were repeated three times, and all data were analyzed by Duncan's multiple range test following two-way ANOVA analysis. Statistical analyses were carried out using Microsoft Excel (Version 2007, Microsoft Corporation, Washington, DC, USA) and SPSS (Version 21.0, International Business Machines Corporation, New York, NY, USA) software, and statistical significance was taken as $p<0.05$. The relative expression level was calculated with the formula $2^{-\Delta \Delta \mathrm{Ct}}=$ normalized expression ratio [64].

Author Contributions: X.-P.W. acquired funding and revised the manuscript; A.-L.L. performed most of the experiments and the data analysis, and also wrote the original draft preparation; Z.W. contributed analysis tools and offered technical support; K.Y. offered gene sequences and designed the research. All authors have read and approved the final version of the manuscript. 
Funding: This research was supported by grants from the National Natural Science Foundation of China (31560549 and 31760566), the Innovation Talent Program of Guizhou Province, P. R. China (2016-4010), as well as the Construction Program of Biology First-class Discipline in Guizhou (GNYL [2017] 009).

Acknowledgments: The authors are grateful for assistance with the manuscript provided by Guang Qiao from Guizhou University.

Conflicts of Interest: The authors declare no conflict of interest.

\section{Abbreviations}

$\begin{array}{ll}\text { ABA } & \text { Abscisic acid } \\ \text { GFP } & \text { Green fluorescent protein } \\ \text { GRF } & \text { Growth regulating factor } \\ \text { HpGRF } & \text { Hylocereus polyrhizu growth regulating factor } \\ \text { miRNA } & \text { Mature microRNA } \\ \text { MIRNA } & \text { Precursor microRNA } \\ \text { PCR } & \text { Polymerase chain reaction } \\ \text { PEG } & \text { Polyethylene glycol } \\ \text { qRT-PCR } & \text { Quantitative real-time polymerase chain reaction } \\ \text { RACE } & \text { Rapid amplification of cDNA ends } \\ \text { RT } & \text { Reverse transcription }\end{array}$

\section{Appendix A}

Table A1. Prediction results of hpo-miR396b target genes.

\begin{tabular}{|c|c|c|c|}
\hline Target Gene ID & Homologous Gene in A. thaliana & Encoding Protein & $\begin{array}{c}\text { Annotation of the Target } \\
\text { Protein }\end{array}$ \\
\hline c56908.graph_c0 & AT2G22840 & AtGRF1, GRF1 & transcription factor \\
\hline c43469.graph_c0 & AT4G37740 & AtGRF2, GRF2 & transcription factor \\
\hline c52862.graph_c0 & AT3G52910 & GRF4, AtGRF4 & transcription factor \\
\hline c39378.graph_c0 & AT2G06200 & GRF6, AtGRF6 & transcription factor \\
\hline c21696.graph_c0 & AT4G24150 & AtGRF8, GRF8 & transcription factor \\
\hline c54658.graph_c0 & AT2G45480 & AtGRF9, GRF9 & transcription factor \\
\hline c56441.graph_c0 & AT2G20180 & PIF1, PIL5 & transcription factor \\
\hline c57103.graph_c0 & AT4G30080 & ARF16 & Auxin response factor \\
\hline c60026.graph_c0 & AT5G13220 & JAZ10, TIFY9, JAS1 & protein binding \\
\hline c53553.graph_c0 & AT1G73960 & TFIID & transcription initiation factor \\
\hline c49149.graph_c0 & AT5G15020 & SNL2 & - \\
\hline c80735.graph_c0 & AT1G11870 & SRS, OVA7, ATSRS & Nucleotide binding \\
\hline c60533.graph_c0 & AT3G14110 & FLU & - \\
\hline c63676.graph_c0 & AT5G03960 & IQD12 & calmodulin binding \\
\hline c62238.graph_c0 & AT3G12580 & HSP70 ATHSP70 & stress response protein \\
\hline c67010.graph_c0 & AT4G09020 & ATISA3, ISA3 & Material metabolism \\
\hline c56337.graph_c0 & AT1G04050 & CPR30 & Stress response protein \\
\hline c81492.graph_c0 & AT2G31830 & 5PTase14 & Nuclear protein \\
\hline c44847.graph_c0 & AT5G52460 & protein TONSOKU-like & Nuclear protein \\
\hline
\end{tabular}

"-" indicates that the target gene was not annotated to a particular function.

Table A2. Primer sequences used in the article.

\begin{tabular}{cccc}
\hline Gene Name & Primer & Primer Sequence $\left(5^{\prime} \rightarrow \mathbf{3}^{\prime}\right)$ & Use \\
\hline \multirow{2}{*}{$h p o-M I R 396 b$} & Forward & ACCTTTCTCTCTCTCGTCTTCT & Gene Clone \\
& Reversal & TGCGAGATGGAGAGGCAATT & Gene Clone \\
\hline \multirow{2}{*}{ HpGRF6 } & $\begin{array}{c}\text { Forward } \\
\text { Reversal }\end{array}$ & TCTTGAAATGATGAGTAATACTACTTCTACTACAAC & TCCCACCTTCTCCCTTCTCTTGAAC \\
\hline \multirow{2}{*}{ HpGRF6 } & Forward & CAGTGGTCTCACAACATGATGAGTAATACTACTTC & \multirow{2}{*}{ Subcellular Localization } \\
& Reversal & CAGTGGTCTCATACAACCTCGTGATGATGAGGCC & \\
\hline
\end{tabular}


Table A2. Cont.

\begin{tabular}{|c|c|c|c|}
\hline Gene Name & Primer & Primer Sequence $\left(5^{\prime} \rightarrow 3^{\prime}\right)$ & Use \\
\hline \multirow{3}{*}{ hpo-miR396b } & Stem-loop RT & $\begin{array}{l}\text { GTCGTATCCAGTGCAGGGTCCGAGGTATTCGCACTG } \\
\text { GATACGACTTCAAGA }\end{array}$ & cDNA Synthesis \\
\hline & Forward & CGGCGGTTCCACAGCTTTC & \multirow{2}{*}{ qRT-PCR } \\
\hline & Reversal & CCAGTGCAGGGTCCGAGGT & \\
\hline \multirow{2}{*}{ HpGRF6 } & Forward & ACTGCTGGTATCCCTGTTCC & \multirow{2}{*}{ qRT-PCR } \\
\hline & Reversal & TGCСTCTTTTGAACATCTCC & \\
\hline \multirow{2}{*}{ U6 } & Forward & GGGGACATCCGATAAAATTGG & \multirow{2}{*}{ qRT-PCR } \\
\hline & Reversal & GATTTGTGCGTGTCATCCTTG & \\
\hline \multirow{2}{*}{ RP40S } & Forward & GACACTGATTCTCCTTTGCGTTAT & \multirow{2}{*}{ qRT-PCR } \\
\hline & Reversal & CCTTTGGTCTCCTCTGGCTCT & \\
\hline
\end{tabular}

\section{References}

1. Bartel, D.P. MicroRNAs: Genomics, biogenesis, mechanism, and function. Cell 2004, 116, 281-297. [CrossRef]

2. Zhang, B.H.; Stellwag, E.J.; Pan, X.P. Large-scale genome analysis reveals unique features of microRNAs. Gene 2009, 443, 100-109. [CrossRef]

3. Mallory, A.C.; Bouché, N. MicroRNA-directed regulation: To cleave or not to cleave. Trends Plant Sci. 2008, 13, 359-367. [CrossRef] [PubMed]

4. Bao, N.; Lye, K.W.; Barton, M.K. MicroRNA binding sites in Arabidopsis class III HD-ZIP mRNAs are required for methylation of the template chromosome. Dev. Cell 2004, 7, 653-662. [CrossRef]

5. Khraiwesh, B.; Arif, M.A.; Seumel, G.I.; Ossowski, S.; Weigel, D.; Reski, R.; Frank, W. Transcriptional control of gene expression by microRNAs. Cell 2010, 140, 111-122. [CrossRef] [PubMed]

6. Wu, L.; Zhou, H.Y.; Zhang, Q.Q.; Zhang, J.G.; Ni, F.R.; Liu, C.; Qi, Y.J. DNA methylation mediated by a microRNA pathway. Mol. Cell 2010, 38, 465-475. [CrossRef]

7. Xie, M.; Zhang, S.; Yu, B. MicroRNA biogenesis, degradation and activity in plants. Cell Mol. Life Sci. 2015, 72, 87-99. [CrossRef] [PubMed]

8. Sunkar, R.; Li, Y.F.; Jagadeeswaran, G. Functions of microRNAs in plant stress responses. Trends Plant Sci. 2012, 17, 196-203. [CrossRef]

9. Elton, T.S.; Yalowich, J.C. Experimental procedures to identify and validate specific mRNA targets of miRNAS. EXCLI J. 2015, 14, 758-790. [CrossRef]

10. Sunkar, R.; Zhu, J.K. Novel and stress-regulated microRNAs and other small RNAs from Arabidopsis. Plant Cell 2004, 16, 2001-2019. [CrossRef]

11. Sunkar, R.; Chinnusamy, V.; Zhu, J.; Zhu, J.K. Small RNAs as big players in plant abiotic stress responses and nutrient deprivation. Trends Plant Sci. 2007, 12, 301-309. [CrossRef]

12. Peng, T.; Sun, H.; Du, Y.; Zhang, J.; Li, J.; Liu, Y.; Zhao, Y.; Zhao, Q. Characterization and expression patterns of microRNAs involved in rice grain filling. PLoS ONE 2013, 8, e54148. [CrossRef]

13. Trindade, I.; Capitão, C.; Dalmay, T.; Fevereiro, M.P.; Santos, D.M. miR398 and miR408 are up-regulated in response to water deficit in Medicago truncatula. Planta 2009, 231, 705-716. [CrossRef]

14. Zhao, M.; Ding, H.; Zhu, J.K.; Zhang, F.; Li, W.X. Involvement of miR169 in the nitrogen-starvation responses in Arabidopsis. New Phytol. 2011, 190, 906-915. [CrossRef]

15. Rodriguez, R.E.; Mecchia, M.A.; Debernardi, J.M.; Schommer, C.; Weigel, D.; Palatnik, J.F. Control of cell proliferation in Arabidopsis thaliana by microRNA miR396. Development 2010, 137, 103-112. [CrossRef]

16. Vander Knaap, E.; Kim, J.H.; Kende, H. A novel gibberellin-induced gene from rice and its potential regulatory role in stem growth. Plant Physiol. 2000, 122, 695-704. [CrossRef]

17. Kim, J.H.; Choi, D.; Kende, H. The AtGRF family of putative transcription factors is involved in leaf and cotyledon growth in Arabidopsis. Plant. J. 2003, 36, 94-104. [CrossRef] [PubMed]

18. Liu, J.; Rice, J.H.; Chen, N.; Baum, T.J.; Hewezi, T. Synchronization of developmental processes and defense signaling by growth regulating transcription factors. PLoS ONE 2014, 9, e98477. [CrossRef] [PubMed]

19. Jones-Rhoades, M.W.; Bartel, D.P. Computational identification of plant microRNAs and their targets, including a stress-induced miRNA. Mol. Cell 2004, 14, 787-799. [CrossRef] 
20. Jones-Rhoades, M.W.; Bartel, D.P.; Bartel, B. MicroRNAs and their regulatory roles in plants. Annu. Rev. Plant Biol. 2006, 57, 19-53. [CrossRef]

21. Omidbakhshfard, M.A.; Proost, S.; Fujikura, U.; Mueller-Roeber, B. Growth-Regulating Factors (GRFs): A small transcription factor family with important functions in plant biology. Mol. Plant 2015, 8, 998-1010. [CrossRef]

22. Vaillant, F.; Perez, A.; Davila, I.; Dornier, M.; Reyne, M. Colorant and antioxidant properties of red-purple pitahaya (Hylocereus sp.). Fruits 2005, 60, 3-12. [CrossRef]

23. Ramli, N.S.; Brown, L.; Ismail, P.; Rahmat, A. Effects of red pitaya juice supplementation on cardiovascular and hepatic changes in high-carbohydrate, high-fat diet-induced metabolic syndrome rats. BMC Complement. Altern. Med. 2014, 14, 189. [CrossRef]

24. Fan, Q.J.; Yan, F.X.; Qiao, G.; Zhang, B.X.; Wen, X.P. Identification of differentially-expressed genes potentially implicated in drought response in pitaya (Hylocereus undatus) by suppression subtractive hybridization and cDNA microarray analysis. Gene 2014, 533, 322-331. [CrossRef]

25. Nong, Q.; Zhang, M.; Chen, J.; Zhang, M.; Cheng, H.; Jian, S.; Lu, H.; Xia, K. RNA-Seq De Novo Assembly of Red Pitaya (Hylocereus polyrhizus) Roots and Differential Transcriptome Analysis in Response to Salt Stress. Tropical Plant. Biol. 2019, 1-12. [CrossRef]

26. Shabalina, S.A.; Koonin, E.V. Origins and evolution of eukaryotic RNA interference. Trends Ecol. Evol. 2008, 23, 578-587. [CrossRef]

27. Tanzer, A.; Stadler, P.F. Molecular evolution of a microRNA cluster. J. Mol. Biol. 2004, 339, 327-335. [CrossRef]

28. Voinnet, O. Origin, biogenesis, and activity of plant microRNAs. Cell 2009, 136, 669-687. [CrossRef]

29. Lu, J.; Shen, Y.; Wu, Q.; Kumar, S.; He, B.; Shi, S.H.; Carthew, R.W.; Wang, S.M.; Wu, C.I. The birth and death of microRNA genes in Drosophila. Nat. Genet. 2008, 40, 351-355. [CrossRef]

30. Felippes, F.F.; Schneeberger, K.; Dezulian, T.; Huson, D.H.; Weigel, D. Evolution of Arabidopsis thaliana microRNAs from random sequences. RNA 2008, 14, 2455-2459. [CrossRef]

31. Bentwich, I.; Avniel, A.; Karov, Y.; Aharonov, R.; Gilad, S.; Barad, O.; Barzilai, A.; Einat, P.; Einav, U.; Meiri, E.; et al. Identification of hundreds of conserved and nonconserved human microRNAs. Nat. Genet. 2005, 37, 766-770. [CrossRef]

32. Alaba, S.; Piszczalka, P.; Pietrykowska, H.; Pacak, A.M.; Sierocka, I.; Nuc, P.W.; Singh, K.; Plewka, P.; Sulkowska, A.; Jarmolowski, A.; et al. The liverwort Pellia endiviifolia shares microtranscriptomic traits that are common to green algae and land plants. New Phytol. 2015, 206, 352-367. [CrossRef]

33. Lin, P.C.; Lu, C.W.; Shen, B.N.; Lee, G.Z.; Bowman, J.L.; Arteaga-Vazquez, M.A.; Liu, L.-Y.D.; Hong, S.F.; Lo, C.F.; Su, G.M.; et al. Identification of miRNAs and their targets in the liverwort Marchantia polymorpha by integrating RNA-Seq and degradome analyses. Plant. Cell Physiol. 2016, 57, 339-358. [CrossRef]

34. Thomson, D.W.; Bracken, C.P.; Goodall, G.J. Experimental strategies for microRNA target identification. Nucleic Acids Res. 2011, 39, 6845-6853. [CrossRef]

35. German, M.A.; Pillay, M.; Jeong, D.H.; Hetawal, A.; Luo, S.; Janardhanan, P.; Kannan, V.; Rymarquis, L.A.; Nobuta, K.; German, R. Global identification of microRNA-target RNA pairs by parallel analysis of RNA ends. Nat. Biotechnol. 2008, 26, 941-946. [CrossRef]

36. Wu, L.; Zhang, Q.Q.; Zhou, H.Y.; Ni, F.R.; Wu, X.Y.; Qi, Y.J. Rice microRNA effector complexes and targets. Plant Cell 2009, 21, 3421-3435. [CrossRef]

37. Pantaleo, V.; Szittya, G.; Moxon, S.; Miozzi, L.; Moulton, V.; Dalmay, T.; Burgyan, J. Identification of grapevine microRNAs and their targets using high-throughput sequencing and degradome analysis. Plant J. 2010, 62, 960-976. [CrossRef]

38. Addo-Quaye, C.; Eshoo, T.W.; Bartel, D.P.; Axtell, M.J. Endogenous siRNA and miRNA targets identified by sequencing of the Arabidopsis degradome. Curr. Biol. 2008, 18, 758-762. [CrossRef]

39. Zhao, Y.P.; Xu, Z.H.; Mo, Q.C.; Zou, C.; Li, W.X.; Xu, Y.B.; Xie, C.X. Combined small RNA and degradome sequencing reveals novel miRNAs and their targets in response to low nitrate availability in maize. Ann. Bot. 2013, 112, 633-642. [CrossRef]

40. Yang, X.Y.; Wang, L.C.; Yuan, D.J.; Lindsey, K.; Zhang, X.L. Small RNA and degradome sequencing reveal complex miRNA regulation during cotton somatic embryogenesis. J. Exp. Bot. 2013, 64, 1521-1536. [CrossRef]

41. Shamimuzzaman, M.; Vodkin, L. Identification of soybean seed developmental stage-specific and tissue-specific miRNA targets by degradome sequencing. BMC Genom. 2012, 13, 310. [CrossRef] [PubMed] 
42. Ma, X.; Zhang, X.; Zhao, K.; Li, F.; Li, K.; Ning, L.; He, J.; Xin, Z.; Yin, D. Small RNA and degradome deep sequencing reveals the roles of microRNAs in seed expansion in peanut (Arachis hypogaea L.). Front. Plant Sci. 2018, 9, 349. [CrossRef]

43. Liu, W.; Zhou, Y.; Li, X.; Wang, X.; Dong, Y.; Wang, N.; Liu, X.; Chen, H.; Yao, N.; Cui, X. Tissue-Specific regulation of Gma-miR396 family on coordinating development and low water availability responses. Front. Plant Sci. 2017, 8, 1112. [CrossRef]

44. Hewezi, T.; Maier, T.R.; Nettleton, D.; Baum, T.J. The Arabidopsis microRNA396-GRF1/GRF3 regulatory module acts as a developmental regulator in the reprogramming of root cells during cyst nematode infection. Plant Physiol. 2012, 159, 321-335. [CrossRef] [PubMed]

45. Szécsi, J.; Joly, C.; Bordji, K.; Varaud, E.; Cock, J.M.; Dumas, C.; Bendahmane, M. BIGPETALp, a $b H L H$ transcription factor is involved in the control of Arabidopsis petal size. EMBO J. 2006, 25, 3912-3920. [CrossRef] [PubMed]

46. Bao, M.L.; Bian, H.W.; Zha, Y.L.; Li, F.Y.; Sun, Y.Z.; Bai, B.; Che, Z.H.; Wang, J.H.; Zhu, M.Y.; Han, N. miR396a-mediated basic helix-loop-helix transcription factor $b H L H 74$ repression acts as a regulator for root growth in Arabidopsis seedlings. Plant Cell Physiol. 2014, 55, 1343-1353. [CrossRef] [PubMed]

47. Debernardi, J.M.; Rodriguez, R.E.; Mecchia, M.A.; Palatnik, J.F. Functional specialization of the plant miR396 regulatory network through distinct microRNA-target interactions. PLoS Genet. 2012, 8, e1002419. [CrossRef] [PubMed]

48. Sun, P.; Cheng, C.; Lin, Y.; Zhu, Q.; Lin, J.; Lai, Z. Combined small RNA and degradome sequencing reveals complex microRNA regulation of catechin biosynthesis in tea (Camellia sinensis). PLoS ONE 2017, 12, e0171173. [CrossRef]

49. Baucher, M.; Moussawi, J.; Vandeputte, O.M.; Monteyne, D.; Mol, A.; Pérez-Morga, D.; El-Jaziri, M. A role for the miR396/GRF network in specification of organ type during flower development, as supported by ectopic expression of Populus trichocarpa miR396c in transgenic tobacco. Plant Biol. 2012, 15, 892-898. [CrossRef]

50. Bazin, J.; Khan, G.A.; Combier, J.P.; Bustos-Sanmamed, P.; Debernardi, J.M.; Rodriguez, R.; Sorin, C.; Palatnik, J.; Hartmann, C.; Crespi, M. miR396 affects mycorrhization and root meristem activity in the legume Medicago truncatula. Plant. J. 2013, 74, 920-934. [CrossRef]

51. Heidel, A.J.; Clarke, J.D.; Antonovics, J.; Dong, X.N. Fitness costs of mutations affecting the systemic acquired resistance pathway in Arabidopsis thaliana. Genetics 2004, 168, 2197-2206. [CrossRef]

52. Sakuma, Y.; Maruyama, K.; Osakabe, Y.; Qin, F.; Seki, M.; Shinozaki, K.; Yamaguchi-Shinozaki, K. Functional analysis of an Arabidopsis transcription factor, DREB2A, involved in drought-responsive gene expression. Plant. Cell 2006, 18, 1292-1309. [CrossRef]

53. Liu, D.M.; Song, Y.; Chen, Z.X.; Yu, D.Q. Ectopic expression of miR396 suppresses GRF target gene expression and alters leaf growth in Arabidopsis. Physiol. Plant. 2009, 136, 223-236. [CrossRef]

54. Beltramino, M.; Ercoli, M.F.; Debernardi, J.M.; Goldy, C.; Rojas, A.M.L.; Nota, F.; Alvarez, M.E.; Vercruyssen, L.; Inzé, D.; Palatnik, J.F.; et al. Robust increase of leaf size by Arabidopsis thaliana GRF3-like transcription factors under different growth conditions. Sci. Rep. 2018, 8, 13447. [CrossRef]

55. Chen, L.; Luan, Y.S.; Zhai, J.M. Sp-miR396a-5p acts as a stress-responsive genes regulator by conferring tolerance to abiotic stresses and susceptibility to Phytophthora nicotianae infection in transgenic tobacco. Plant. Cell Rep. 2015, 34, 2013-2025. [CrossRef]

56. Gao, P.; Bai, X.; Yang, L.; Lv, D.K.; Li, Y.; Cai, H.; Ji, W.; Guo, D.J.; Zhu, Y.M. Over-expression of osa-MIR396c decreases salt and alkali stress tolerance. Planta 2010, 231, 991-1001. [CrossRef]

57. Noon, J.B.; Hewezi, T.; Baum, T.J. Homeostasis in the soybean miRNA396-GRF network is essential for productive soybean cyst nematode infections. J. Exp. Bot. 2019, 70, 1653-1668. [CrossRef]

58. Casadevall, R.; Rodriguez, R.E.; Debernardi, J.M.; Palatnik, J.F.; Casati, P. Repression of growth regulating factors by the microRNA396 inhibits cell proliferation by UV-B radiation in Arabidopsis leaves. Plant Cell 2013, 25, 3570-3583. [CrossRef]

59. Dai, X.; Zhao, P.X. psRNATarget: A plant small RNA target analysis server. Nucleic Acids Res. 2011, 39, W155-W159. [CrossRef]

60. Kiełbasa, S.M.; Blüthgen, N.; Fähling, M.; Mrowka, R. Targetfinder.org: A resource for systematic discovery of transcription factor target genes. Nucleic Acids Res. 2010, 38, W233-W238. [CrossRef]

61. Li, X. Infiltration of Nicotiana benthamiana protocol for transient expression via Agrobacterium. Bio-Protocol 2011, 1, e95. [CrossRef] 
62. Chen, C.F.; Ridzon, D.A.; Broomer, A.J.; Zhou, Z.H.; Lee, D.H.; Nguyen, J.T.; Barbisin, M.; Xu, N.L.; Mahuvakar, V.R.; Andersen, M.R. Real-time quantification of microRNAs by stem-loop RT-PCR. Nucleic Acids Res. 2005, 33, e179. [CrossRef] [PubMed]

63. Pant, B.D.; Musialak-Lange, M.; Nuc, P.; May, P.; Buhtz, A.; Kehr, J.; Walther, D.; Scheible, W.R. Identification of nutrient-responsive Arabidopsis and rapeseed microRNAs by comprehensive real-time polymerase chain reaction profiling and small RNA sequencing. Plant. Physiol. 2009, 150, 1541-1555. [CrossRef] [PubMed]

64. Livak, K.J.; Schmittgen, T.D. Analysis of relative gene expression data using real-time quantitative PCR and the $2^{-\Delta \Delta C t}$ method. Methods 2001, 25, 402-408. [CrossRef]

(C) 2019 by the authors. Licensee MDPI, Basel, Switzerland. This article is an open access article distributed under the terms and conditions of the Creative Commons Attribution (CC BY) license (http://creativecommons.org/licenses/by/4.0/). 